\title{
Problems and Countermeasures of Cultivating Autonomous English Learning Ability in Vocational Colleges based on Informationization
}

\author{
Hui Mo*, Xuejuan Yan \\ Guangzhou Sontan Polytechnic College, Guangzhou 511370, China \\ *Corresponding author: Hui Mo, 253347174@qq.com
}

\begin{abstract}
With the advent of $5 \mathrm{G}$ era, it has become an inevitable trend to drive educational modernization with educational informationization. The modern-day education uses science and technology as well as culture in cultivating independent learning as the ultimate goal. However, there are many drawbacks in the system and practical aspects of higher vocational education in which one of it is that the independent learning has been neglected in the learning process. This article analyzed the issues in the autonomous learning of the English language among higher vocational college students and discussed strategies to improve their autonomous learning ability based on informationization to promote bidirectional interaction between teachers and students, cultivate students' consciousness of lifelong learning, improve teachers' technical skills, and perfect the development of a connotative system in higher vocational colleges.
\end{abstract}

Keywords: Informationization; Vocational English; Autonomous learning; Ability cultivation

Publication date: June 2021; Online publication: June 30, 2021

\section{Introduction}

With the acceleration of industrial upgrading and economic structural adjustment, the demand for technical talents in various sectors is ever more urgent. Vocational education provides talents and intellectual supports for social development; thereby, its status has become increasingly prominent. However, at present, there are many issues in the English-language vocational education in China. This country has been facing unprecedented challenges while improving the comprehensive quality of vocational talents as well as in realizing the systematization, modernization, and circumstances of the English-language vocational education. ${ }^{[1]}$ With the constant penetration of information technology, there is a ray of light for the modernization of English-language education driven by informationization in vocational education. With the construction of digital network platforms, the progress in the lifelong education system and students' autonomous learning ability have created a new approach for the cultivation of diversified talents in the English-language vocational education.

\section{Existing issues in autonomous English learning}

\subsection{The need to cultivate students' awareness in goal-setting and self-monitoring}

The autonomous learning ability consists of a series of behaviors such as establishing and planning learning goals, monitoring learning processes, as well as managing learning behaviors. ${ }^{[2]}$ However, at present, most students in higher vocational colleges have no clear goals in regard to their own learning. They do not know the reasons and methods of learning, and it is difficult for them to apply the acquired knowledge to form a system. Students have the habit of following their teacher's instructions to complete an assigned tasks which 
shows that their subjective initiative is weak and an inadequacy in their motivation for learning. In addition to that, in the process of learning English, students rarely plan out their time, balance their learning schedules, monitor the completion of previous goals, or automatically learn English after classes. The ability of students to self-plan and monitor their own learning directly affects their efficiency and impact of learning English. In the long run, students who are in a state of without goals or plans would find it difficult to stimulate their own interest and improve their learning performances.

\subsection{Increasing attentiveness toward skills cultivation}

Autonomous learning does not only contribute to the improvement of students' academic performances in school, but also acts as the basis for their lifelong learning and development. However, traditional teaching is still prevalent in higher vocational colleges. On the one hand, teachers overly emphasize on imparting knowledge but neglect to cultivate students' innovative spirit, abilities, and personality. This in turn results in students being passive during classes and in gaining knowledge. On the other hand, various learning contents are added to a long list of goals and teachers need to complete the syllabus within limited time. The traditional teaching method may accomplish goals or plans but it emphasizes on passive acceptance and mastery while neglecting discovery and exploration. In this way, the cognition process of students would be of passive acceptance and subdued to memorization. The authoritativeness of the traditional teaching method compels students to have a "listen more and think less" attitude in class whereby their critical and speculative abilities would gradually diminish. Differing from traditional discipline-oriented values and knowledge, the current vocational education system provides a new ideological impetus for the reform of vocational education in which vocational characteristics would be highlighted and the system would focus on cultivating students' vocational abilities. ${ }^{[3]}$

\subsection{The need to strengthen schools' autonomous English learning system}

Both the teachers and students have a common goal which is to improve the students' independent English learning abilities. At present, higher vocational colleges have not established a comprehensive autonomous learning resource system and students have scarce understanding of the methods for autonomous learning. In regard to students' autonomous learning, relying only on multimedia and digital teaching platforms while lengthening the time of online lessons would greatly reduce face-to-face lessons. These practices only express an urgency for quick success and instant benefits. Students have not been guided or trained for autonomous learning. Hence, there is no guarantee to their learning efficiency and the effect from this kind of learning. During the epidemic, some schools hastily construct online courses which results in an imperfect course system with incomplete teaching contents and resources which shows that the online selfstudy is just a formality. In addition to that, there are no autonomous learning centers and even the multimedia equipment in schools are not well-furbished. Students have to rely on their own mobile phones or laptops during online courses. All these issues add on to students lack of direction and poor interests in learning. Thereby, no improvement is seen in the students' independent learning ability or quality. 


\section{Cultivation strategy}

Table 1. Cultivation strategies

\begin{tabular}{ccccc}
\hline Step & Trigonometry strategies & Cyclic strategies & Supporting strategies & Function \\
\hline Step one & Before class & Teaching design & Information assistance & Preparation \\
Step two & During class & Teaching process & Teachers' guidance & Reinforcement \\
Step three & After class & Teaching evaluation & Students' autonomy & Introspection \\
\hline
\end{tabular}

\subsection{Trigonometry strategies before, during, and after lessons}

First, teachers should prepare prior lessons in which the students' needs should be understood to plan out curriculums and learning objectives. The English-language learning is different from other subjects as it requires intensive trainings and consolidations to improve students' language skills. Hence, prior actual lesson, teachers should introduce the learning objectives of the course as well as to provide a class schedule. With that in mind, students should then map out short and long-term learning plans under the teachers' guidance in addition to clear division of tasks between teachers and students for each unit. In the teaching process, teachers should deliver task lists on a platform so that students may be able to carefully prepare according to the guide given while understanding the learning contents. In this way, students would be given opportunities to arrange their own learning goals, make a habit out of previewing and preparing prior lessons, and put forward questions. This would eventually effectively enhance students' autonomous learning ability. In simpler terms, prior lessons, teachers should utilize the online platforms to create online course resources such as micro-class videos, text-related videos, audio, website links, and other resources. A Wechat group should also be set up for timely communication, supervision of preview tasks in regard to students' independent preparation prior classes, and teachers would be able to follow up with students' daily English learning in real situations as well as to understand issues faced by students in order to carry out targeted lesson planning.

The second is reinforcement in class. On the one hand, teachers should appropriately implement various English vocabulary strategies including memorizing, listening, reading, writing, and translating during lessons. This is to train students in their conscious application of relevant strategies in the process of learning English and as a guidance for them to employ effective strategies that are suitable for themselves. For example, activities such as brainstorming, skimming, filling in the blanks, and jigsaw reading can be conducted to help students understand texts better, learn relevant vocabularies, and improve their communication competence. On the other hand, teachers can also design project-orientated teaching plans according to the unit contents and the course direction. Teaching contents can then be integrated into projects or tasks while allowing students to learn and discuss in groups under guidance. Project-oriented teachings allow knowledge systems to be more ideal and systematic. The output-oriented teaching allows students to feel a sense of achievement as they are able to produce their own works after learning a unit. When assigning homework, teachers may also request their students to scan a two-dimensional code to watch relevant videos which can be a combination of the online and offline methods. The whiteboard can also be effectively utilized in classes whereby keywords can be written on it to help students recap later on.

The third involves reflection after lessons. Both teachers and students should be encouraged to have reflective diaries. In this way, teachers may reflect on the problems in teaching designs and teaching practices to improve measures while students may reflect on the deficiencies in their learning process and the areas that are required to be strengthened. Teachers should then be committed to collect students' daily self-evaluations, peer evaluations, and reflection diaries to organize them into students' development files to keep a tab on their progress. In this way, students will be more attentive and serious about their learning 
while teachers would have access to students' progress databases which provide more materials for scientific research.

\subsection{Cyclic strategies of teaching design, process, and evaluation}

First, teaching designs should be fitting for tasks and abilities. Compared to the traditional teaching method, the information-based education teaching design asserts higher requirements for English teachers. ${ }^{[4]}$ Teaching design activities may be arranged from easy to difficult and from individual to whole in which the levels are linked. Teaching designs should include four characteristics which are "comprehensive, accurate, ideological, and interesting."

In regard to the comprehensive characteristic, teachers should use online resources to thoroughly collect and select materials. Teaching resources and materials including video, audio, pictures, data, etc. which are linked to higher vocational careers allow English lessons to be more visual, tangible, and multimodal which would reflect the uniqueness of vocational education.

In terms of an accurate teaching design, this characteristic strives for clear goals, accurate knowledge, key points or issues, reasonable time allocation, and foreseeability. Based on students' fundamental understandings and the difficulty of a specific learning content, an organic unified learning content which displays knowledge, abilities, processes, methods, emotions, and attitude can be designed.

In terms of the ideological characteristic, ideological and political theories teachings should be implemented in English language courses. While teaching students, dominant or recessive ideological elements of patriotism would be sown in their hearts; hence, developing a strong sense of patriotism. The English language is a fundamental and international language, hence, by making full use of it, it may function as a cultural carrier in the spread of China's voice around the world.

With the interesting characteristic, knowledge and contents may be integrated into activities to stimulate students' learning enthusiasm, patriotism, and cultivate their feelings toward their home and country.

Second, the teaching process should achieve the integration of activities, ideas, language, and skills. Offline classroom is a place for teachers and students to communicate or interact and for students to display their skills. In classrooms, teachers may conduct various interesting activities such as English debate, role playing, topic discussions, PowerPoint presentations, and so on. In combination with numerous online interactive methods such as photo check-in, candidate selection, quick answer, and discussions, etc., teachers are given the opportunity to create a relaxed environment to promote positive interactions with students. With the break-down of teaching objectives, teachers may use multi-modal resources and introduce activities or scenarios to enhance cooperative learning among students. In order to encourage students to overcome psychological barriers, speaking more boldly, and to ensure cooperative learning in groups, teachers should learn a few methods to guide their students. Teachers should be attentive to their students' level of learning as well as the basis of psychological comparison in addition to learning students' individual differences and respecting their cognitive levels. In regard to that, teachers should select appropriate methods, utilizing multi-angle communication with students, maximizing students' innovation abilities, promote active learning, as well as unifying teachers and students together.

Thirdly, with teaching evaluations, the integration of students' independent thinking and selfmanagement can be achieved. Teaching evaluation benefits in promoting and guiding the learning process. The constructs in evaluation forms would clarify students' learning objectives and the direction of their efforts. Hence, students indirectly learn self-evaluation to enhance independent and autonomous learning. In this way, "evaluation promotes learning and teaching" would be advocated and the results would be tested to improve students' autonomous learning ability. After class, students should be encouraged to reasonably utilize online teaching assistance software for evaluation while teachers should check these 
learning data in a timely manner to monitor students' learning levels, rectifying existing problems, and focus on solving common issues. Students' excellent works should also be uploaded to the schools' websites and public accounts so that students will be able to feel a sense of achievement from learning and eventually, boost their confidence.

Teaching designs are powerful guarantees for a smooth teaching process. The operability of the teaching process directly affects the achievement of goals while the realization of these teaching goals verifies the rationality of teaching designs. They depend, yet restrict one another, form circulation patterns, and promote the effective development of teaching.

\subsection{Supporting strategies of information assistance, teachers' guidance, and students' autonomy}

With information assistance, this information age conveniently integrates high-quality teaching resources of English courses into online teaching platforms so that the teachers and students are able to communicate and independently learn English for the latter. The after-class platforms automatically assemble relevant data such as learning time and homework while intelligently analyze the monitoring reports of students' learning status. They also provide reference data for teachers and act as strong supports for personalized teaching. The application of information technology significantly reduces the workload of English teachers. It does not only provide abundant resources but also, builds a bridge for situational learning, cooperation, mutual assistance, as well as discussions and interactions in the English-language curriculum; hence, teaching becomes more vivid and efficient. ${ }^{[5]}$

Second, utilizing teachers' guidance. With information explosion, teachers are able to build up their knowledge thereby, having excellent English quality in addition to pedagogy, psychology, and other related knowledge. On the other hand, teachers would need to have the ability to utilize modern-day information technology including multimedia and network technology. While guiding students to gain knowledge, they should also be guided to make practical plans, improve metacognitive and cognitive strategies in the English-language learning, actively participate in thinking, and cultivate comprehensive abilities such as critical thinking. As the old saying goes, "Getting closer to teachers first, then, following their ways," teachers should first improve their interaction with students, create equal and friendly environments, as well as shorten psychological distances in order for students to speak freely and express their own views. Eventually, students would follow their teachers' pace and complete learning tasks autonomously.

Third, being student-centered is important. The subject of autonomous learning is the students. It is advocated that knowledge can be acquired by independent learning under guidance and encouragement of teachers. ${ }^{[6]}$ The expression of opinions and engagement in critical thinking activities, development of the understanding process, gaining knowledge to achieve learning goals, and the integration of existing knowledge to solve new problems would enable students to generate multi-perspective views and think creatively. In the whole learning activity, students should actively participate, explore, collect information, conduct comprehensive analysis and judgment, and finding out solutions. With informationization, students may independently search, assemble, and sort out digital materials related to the English language which would not only cultivate their autonomous learning ability but also strengthen their application of modern technology and effective sharing of resources.

\section{Practical significance}

\subsection{Expand two-way communication}

In this information age, social media offers a more convenient way for learners to learn independently. The classroom ecosystem has improved while students have gradually become the main focus of education. Through the introduction of online teaching platforms, students can easily and freely communicate with 
teachers before, during, and after classes, as well as conduct discussions among group members. In this way, the classroom environment is significantly livelier. Hence, learning is not only limited to time and space. Students would then be able to appreciate multi-modal teaching resources and produce their own works. They would also have multi-sensory access to English knowledge, participate in specific activities, utilize their own multi-modal resources, and lay excellent foundations for the use of the English language in actual situations. If teachers paid more attention to student-centered teachings, students would have more opportunities to communicate and immerse themselves in learning the English language. In this way, interactions between teachers and students are enhanced and a two-way synergy would be gradually reflected.

\subsection{Establishing the concept of lifelong learning}

With the advent of the knowledge economy, merely imparting knowledge is inadequate and not all human knowledge can be imparted to learners. Hence, education needs to be transformed and the emphasis should be on cultivating students' learning ability especially in regard to lifelong learning. With the continuous progress of information technology and the rapid updates in modern society, learning cannot be only restricted to the book level. Lifelong learning is not only an inevitable requirement to adapt to social development, but it is also a need for survival. Students with an established concept of lifelong learning will have the desire to pursuit knowledge which eventually, promote continual learning while utilizing advanced tools and scientific methods to acquire knowledge independently.

\subsection{Promoting improvement of teachers' information literacy skills}

In pre-service trainings and teachers' career development, the emphasis is on training English teachers' knowledge and skills, however, the training of information technology is lacking. ${ }^{[7]}$ This new era raises the requirements in terms of information literacy skills among English teachers. Their skills directly affect the English-language learning among students hence, schools should vigorously promote the training of English teachers' teaching skills while designing an incentive system to improve the capacity and encourage teachers to employ information technology in their practice. This would solve the existing issues in teachings and eventually improve its quality.

\subsection{Enriching online teaching resources and the learning environment on campus}

Based on the nation's new strategy of vocational education, colleges are required to create online courses. By enriching online resources, convenient, flexible, and personalized information would be provided while establishing autonomous learning environments which promote lifelong learning and enhance digital skills. These courses can select resources from exceptional teachers and avoid losses caused by the demission of teachers. By upgrading and promoting information technology, the efficiency of the management can be improved via informationization supervision systems, comprehensive development of basic courses, and improvement of higher vocational teachings to cultivate high-quality talents with lifelong learning skills.

\section{Conclusion}

In view of educational informationization, this article focused on the issues pertaining higher vocational English-language education and discussed strategies to enrich and promote the efficiency of Englishlanguage education from a multidimensional angle. Moreover, this paper analyzed countermeasures of triangle strategies, cyclic strategies, and supporting strategies in training students' autonomic English learning ability. By cultivating autonomic learning among students, bilateral communication between students and teachers can be promoted, the concept of lifelong learning can be established, online resources 
can be enriched and the learning environment on campus can also be improved. These would not only accelerate the modernization of education but also promote the connotative development of higher vocational education thus, cultivating international high-quality skilled talents for the society.

\section{Funding}

Supported by Guangdong University Innovation Young Talents Project, "Research on the Cultivation of English Autonomous Learning Ability in Higher Vocational Colleges Based on SPOC" (Project number: 2020WQNCX240); Achievements of the visiting period of Guangdong University of Foreign Studies.

\section{Disclosure statement}

The author declares no conflict of interest.

\section{References}

[1] Opinions of the Ministry of Education on strengthening the construction, application and management of online open courses in colleges and universities. Bulletin of the State Council of the People's Republic of China, 2015: 48-50.

[2] Xu JF, 2014, Research on the status quo and thinking of Chinese college students' autonomous learning ability. Language Education, (11).

[3] Kaplan AM, Haenlein M, 2016, Higher education and the digital revolution: about MOOCs, SPOCs, social media, and the Cookie Monster. Business Horizons, 59(4): 441-50.

[4] Zhang E, Zhang W, Jin C, 2018, SPOC-based flipped classroom of college English: construction of an effective learning model. Technology Enhanced Foreign Language Education, 13(1): 37-40.

[5] Han X, Ren F, 2020, On the improvement of vocational college students' information literacy in the era of "internet + ". Education and Careers, (17): 103-7.

[6] Pang WG, 2003, Theory and strategy of independent learning - learning and teaching, East China Normal University Press, Shanghai.

[7] Gengxing, 2020, SPOC-based hybrid collaborative development model of 333 for pre-service and post-service learners. Education and Careers, (11): 102-6. 